\title{
Correction to: Revisiting the Twentieth Century Through the Lens of Generation X and Digital Games: A Scoping Review
}

\author{
Hannah R. Marston ${ }^{1}$ María del Carmen Miranda Duro ${ }^{1,2}$ \\ Published online: 13 April 2020 \\ (c) Springer Science+Business Media, LLC, part of Springer Nature 2020
}

\section{Correction to: The Computer Games Journal https://doi.org/10.1007/s40869-020-00099-0}

In the original article, the authors noticed a few errors in the Abstract and in a few textual parts. The following text passages are affected.

Ln 7-9: 4 papers were irretrievable, 138 duplicated papers were removed, leaving 3048 were assessed for eligibility and 3026 were excluded.

It should read:

2520 papers recorded access, with 644 papers unable to access, 138 duplicated papers were removed, leaving 1738 were assessed for eligibility and 1707 were excluded.

Ln 9: Articles $(n=22) \ldots$.

It should read:

Articles $(\mathbf{n}=\mathbf{2 0})$

Methods Section:

Pg7, Ln7 Twenty-two records it should read: Twenty records

Pg7, Figure. Under the Screening 1st square, the number 644

Pg7, Figure. Under the Eligibility 1st square, the number 2382 should be changed to $\mathbf{1 7 3 8}$

The original article can be found online at https://doi.org/10.1007/s40869-020-00099-0.

Hannah R. Marston

Hannah.Marston@open.ac.uk

María del Carmen Miranda Duro

marstonhannah@hotmail.com

1 Health and Wellbeing Priority Research Area, School of Health, Wellbeing and Social

Care, The Open University, Ground Floor, Stuart Hall Building, Milton Keynes,

Buckinghamshire MK7 6BP, UK

2 Department of Physiotherapy, Medicine and Biomedical Sciences, Faculty of Health Sciences,

Oza Campus, University of A Coruña, 15006 A Coruña, Spain 
Pg7, Figure. Under the Eligibility 1st square, the number 2351 should be changed to $\mathbf{1 7 0 7}$

P7, Figure. Under the Eligibility 2nd square, the number 12 should be changed to 11

Results Section: General Characteristics of Studies:

Pg9, Ln2 2351 were excluded. It should read 1707 were excluded. Pg9, Ln2 19 papers had full text assessment. It should read 20 papers had full text assessment

Pg9, The majority of the articles were published in $1997(n=4)$ and $1999(n=$ 4) with one study published in 1971. Likewise, only one study was published in the years 1980, 1983, 1985, 1986, 1988, and 1989 respectively. Two studies were published in 1994.

It should read:

The majority of the articles were published in $1999(\mathrm{n}=5), 1997(\mathrm{n}=$ 3), $1989(n=2), 2000(n=2)$. In each of the following years, 1971, 1980, 1985, 1986, 1988, 1994, 1996, and 1998 one study was published.

Pg16, Table \#10 - This study was published in the USA 